\title{
The cystic fibrosis transmembrane conductance regulator is an extracellular chloride sensor
}

\author{
Steven D. Broadbent • Mohabir Ramjeesingh • \\ Christine E. Bear • Barry E. Argent • Paul Linsdell • \\ Michael A. Gray
}

Received: 1 August 2014 / Revised: 22 September 2014 / Accepted: 23 September 2014 / Published online: 4 October 2014

(C) The Author(s) 2014. This article is published with open access at Springerlink.com

\begin{abstract}
The cystic fibrosis transmembrane conductance regulator (CFTR) is a $\mathrm{Cl}^{-}$channel that governs the quantity and composition of epithelial secretions. CFTR function is normally tightly controlled as dysregulation can lead to lifethreatening diseases such as secretory diarrhoea and cystic fibrosis. CFTR activity is regulated by phosphorylation of its cytosolic regulatory $(\mathrm{R})$ domain, and ATP binding and hydrolysis at two nucleotide-binding domains (NBDs). Here, we report that CFTR activity is also controlled by extracellular $\mathrm{Cl}^{-}$concentration $\left(\left[\mathrm{Cl}^{-}\right]_{\mathrm{o}}\right)$. Patch clamp current recordings show that a rise in $\left[\mathrm{Cl}^{-}\right]_{\mathrm{o}}$ stimulates CFTR channel activity, an effect conferred by a single arginine residue, R899, in extracellular loop 4 of the protein. Using NBD mutants and ATP dose response studies in WT channels, we determined that $\left[\mathrm{Cl}^{-}\right]_{\mathrm{o}}$ sensing was linked to changes in ATP binding energy at NBD1, which likely impacts NBD dimer stability. Biochemical measurements showed that increasing $\left[\mathrm{Cl}^{-}\right]_{\mathrm{o}}$ decreased the intrinsic ATPase activity of CFTR mainly through a reduction in maximal ATP turnover. Our studies indicate that sensing $\left[\mathrm{Cl}^{-}\right]_{\mathrm{o}}$ is a novel mechanism for regulating CFTR activity and suggest that the luminal ionic environment is an important physiological arbiter of CFTR function, which has significant implications for salt and fluid homeostasis in epithelial tissues.
\end{abstract}

S. D. Broadbent $\cdot$ B. E. Argent • M. A. Gray $(\bowtie)$ Epithelial Research Group, Institute for Cell \& Molecular Biosciences, Newcastle University, Newcastle upon Tyne NE2 4HH, UK

e-mail: m.a.gray@ncl.ac.uk

M. Ramjeesingh • C. E. Bear

Hospital for Sick Children and Departments of Biochemistry and

Physiology, University of Toronto, Toronto, ON, Canada

S. D. Broadbent $\cdot$ P. Linsdell

Department of Physiology \& Biophysics, Dalhousie University,

Halifax, NS, Canada
Keywords CFTR · Channel gating · Epithelial ion transport . Electrophysiology

\section{Introduction}

The cystic fibrosis transmembrane conductance regulator (CFTR) is an anion channel which plays a crucial role in regulating salt and fluid transport in the airways, sweat glands and the gastrointestinal and genital tracts $[36,26]$. Loss of function mutations in CFTR cause the fatal inherited disease cystic fibrosis (CF) [32], while overactive CFTR in the GI tract leads to secretory diarrhoea [41]. CFTR is composed of two transmembrane domains (TMDs), each consisting of six transmembrane spans connected by extracellular loops (ECLs), plus two cytosolic nucleotide-binding domains (NBDs) and a large regulatory (R) domain $[36,32]$. There are also a number of positively charged residues in the ECLs and outer pore $[32,19]$. The positions of these residues and the other major domains of CFTR are shown in Fig. 1a. Opening of CFTR requires cAMP/PKA-dependent phosphorylation of the R domain followed by the binding of two ATP molecules; one to site 1 of NBD1 and one to site 2 of NBD2, which induces dimerisation of the NBDs in a head-to-tail fashion and leads to opening of the 'gate' located in the TMDs (see [23] for a recent review). Channel closing is caused by ATP hydrolysis at site 2 and the subsequent release of ADP and Pi drives disassembly of the NBD dimer [16, 40]. Because site 1 lacks a number of essential (conserved) residues necessary for efficient nucleotide hydrolysis, ATP remains bound at this site much longer than at site 2 . Therefore, it is believed that events at site 2 mainly terminate channel openings $[6,2,5]$. However, recent work indicates that ATP binding to site 1 also contributes to the stability of the open state [49], and therefore has an important, but less well-defined, role in CFTR gating. 
Fig. 1 Molecular structure of CFTR. a Cartoon of the CFTR protein showing the location and charge of the all amino acids mutated in this study. Note that the extracellular loops are not drawn to scale. b Threedimensional homology model of CFTR based on the work of Dalton et al. [14], using PyMol software indicating the relative positions of R899, W401 and E1371 residues to other regions of note. Note that the homology model lacks the $\mathrm{R}$ domain and that in the right hand diagram, the extracellular surface of CFTR is orientated to face the reader.

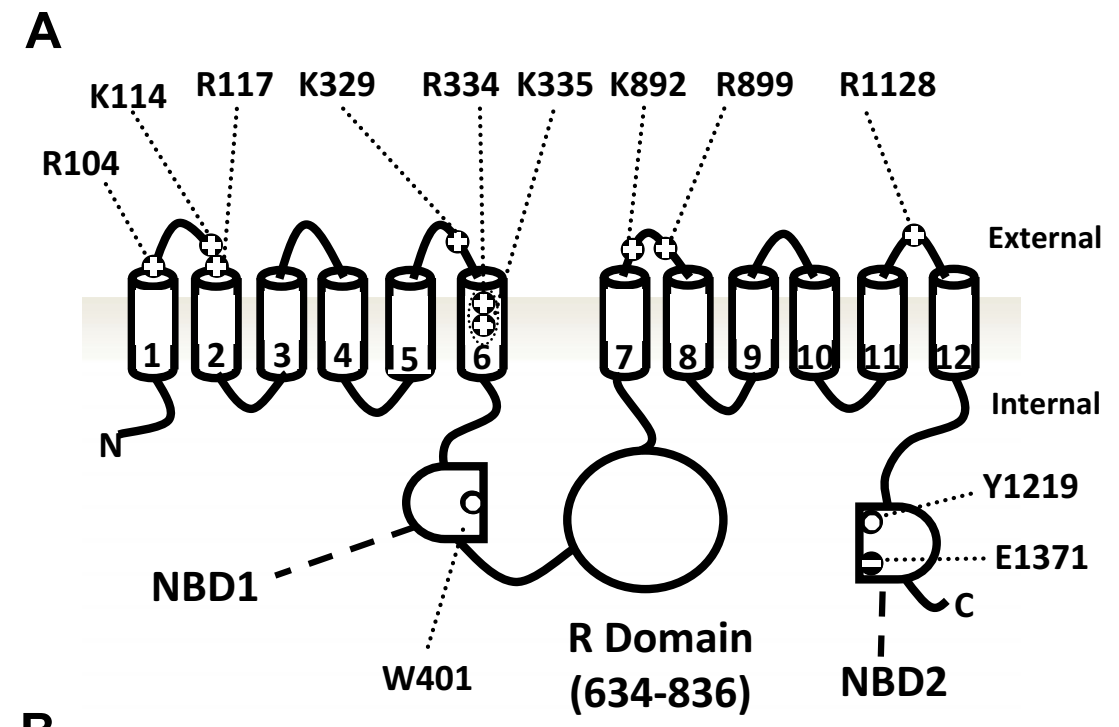

B
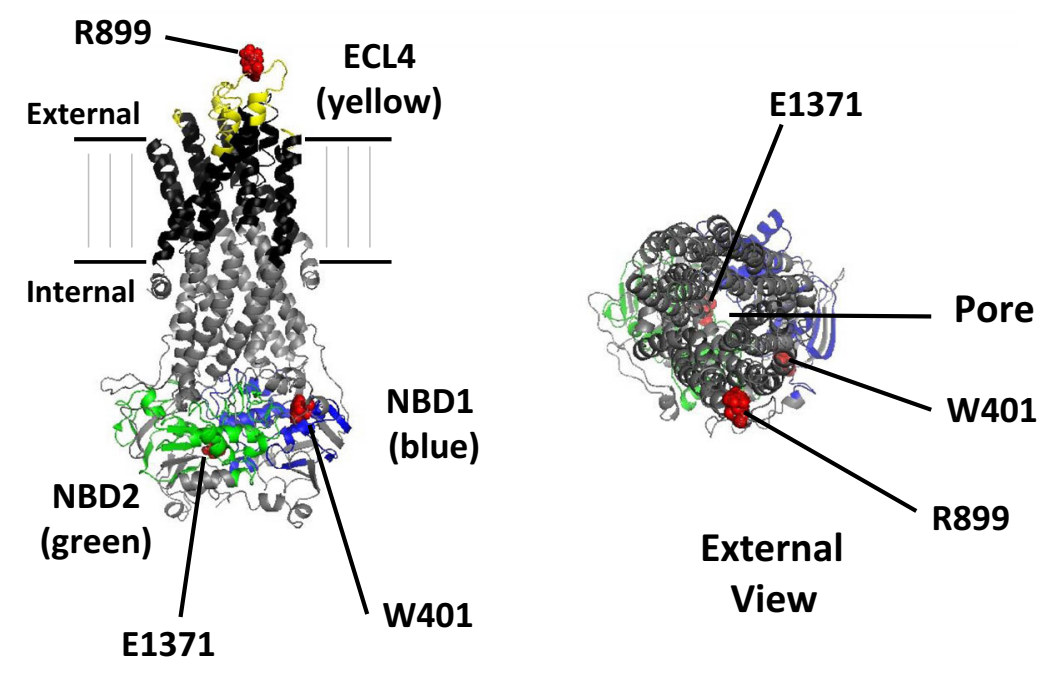

Extracellular (i.e. luminal in the physiological situation) $\mathrm{Cl}^{-}$concentration $\left(\left[\mathrm{Cl}^{-}\right]_{0}\right)$ can regulate the function of CFTR. We have shown that an increase in $\left[\mathrm{Cl}^{-}\right]_{\mathrm{o}}$ enhances CFTR activity, both in cell-free, inside out, as well as whole cell patch clamp recordings $[29,44]$, indicating that a change in channel gating, not channel numbers, underlies the response. Others have reported that a reduction in $\left[\mathrm{Cl}^{-}\right]_{\mathrm{o}}$ alters the $\mathrm{HCO}_{3}{ }^{-} / \mathrm{Cl}^{-}$permeability ratio and the conductance of the channel $[35,27]$. Because most CFTR-expressing epithelia secrete substantial amounts of $\mathrm{Cl}^{-}$and $\mathrm{HCO}_{3}{ }^{-}$(up to $140 \mathrm{mM}$ $\mathrm{HCO}_{3}{ }^{-}$in the case of the pancreas [3]), and because the concentrations of these anions in the luminal fluid varies under physiological conditions [39, 25, 33, 37, 43], such studies have led to the speculation that CFTR may be regulated by the $\mathrm{Cl}^{-}$content of its own secretions [44, 27]. However, how $\left[\mathrm{Cl}^{-}\right]_{\mathrm{o}}$ is sensed by epithelial cells and how changes in $\left[\mathrm{Cl}^{-}\right]_{\mathrm{o}}$ are communicated to CFTR in order to modulate its gating, permeability and conductance are fundamentally important questions that have not been answered.

The goal of this study was to establish if CFTR itself could act as an extracellular $\mathrm{Cl}^{-}$sensor and control its own gating. To address this question, wild type (WT) and mutant forms of CFTR were heterologously expressed in mammalian cells and the response to changes in $\left[\mathrm{Cl}^{-}\right]_{\mathrm{o}}$ studied using the patch clamp technique. CFTR was also purified and the effect of $\left[\mathrm{Cl}^{-}\right]$on its ATPase activity measured to determine if $\mathrm{Cl}^{-}$ sensing constitutes an intrinsic property of the CFTR protein.

\section{Materials and methods}

Cell culture, plasmids and transfection Plasmids were constructed using either the pIRES2-EGFP (CLONTECH Laboratories, Inc., Mountain View, CA, USA) or pBudCE4.1 
(Invitrogen, Burlington, ON, Canada) as described previously $[18,7]$. Human embryonic kidney (HEK 293) cells were grown in high-glucose Dulbecco's modified Eagle's medium (DMEM) with $10 \%$ fetal calf serum (FCS), and $1 \%$ penicillin and streptomycin in a $5 \% \mathrm{CO}_{2}$ humidified atmosphere at $37^{\circ} \mathrm{C}$. HEK cells grown on glass coverslips were transiently transfected with WT or mutant forms of human CFTR. Briefly, plasmid DNA was pre-complexed with OptiMEM-withGlutaMAX (Invitrogen, Paisley, UK) and Lipofectamine 2000 (Invitrogen, Paisley, UK) for $15 \mathrm{~min}$. Complexed DNA was then diluted in supplement-free medium to $\sim 0.5 \mu \mathrm{g} / \mathrm{ml}$ and added to the cells. After $6 \mathrm{~h}$ at $37^{\circ} \mathrm{C}$ and $5 \% \mathrm{CO}_{2}$, the medium was replaced with OptiMEM containing $5 \%$ FCS. Transfected cells were identified by epifluorescence and used 2 to 4 days after transfection. Expression levels of the DeltaR-CFTR constructs were augmented by incubating cells at $27^{\circ} \mathrm{C}$ in $5 \mathrm{mM}$ sodium butyrate after transfection [22]. For patch clamp experiments, cells were studied at $\sim 40-50 \%$ confluency on glass coverslips.

Electrophysiology Fast whole cell patch clamp recordings (fWCR) and data analysis were performed as described previously [44]. Whole cell currents were recorded at room temperature with an Axopatch 200B amplifier (Molecular Devices Inc., Wokingham, UK) and steady-state current-voltage (I-V) relationships obtained by holding the membrane potential $\left(V_{\mathrm{m}}\right)$ at $0 \mathrm{mV}$ and clamping to $\pm 100 \mathrm{mV}$ in $20 \mathrm{mV}$ increments for $250 \mathrm{~ms}$, with a 1 -s interval between each pulse. Current amplitudes were calculated at the reversal potential $\left(E_{\text {rev }}\right)$ to $\pm 60 \mathrm{mV}$ and normalised to cell capacitance $(\mathrm{pF})$. The $E_{\text {rev }}$ was obtained by interpolation from I-V plots ( $x$-axis intercept obtained by fitting a fourth-order polynomial to the $\mathrm{I}-\mathrm{V}$ data points). After establishing a fWCR, the standard experimental protocol was to measure: (1) control currents in high $(155.5 \mathrm{mM}) \mathrm{Cl}^{-}$bath solution, followed by forskolin $(10 \mu \mathrm{M})$-stimulated currents (measured after at least 5-min exposure to forskolin, FSK) in (2) high (155.5) $\mathrm{mM} \mathrm{Cl}^{-}$, (3) low (35.5 mM) $\mathrm{Cl}^{-}$and (4) high (155.5) $\mathrm{mM} \mathrm{Cl}^{-}$. The percentage stimulation of CFTR activity by $\mathrm{Cl}^{-}$was calculated by comparing the current amplitude at $-60 \mathrm{mV}$ from the $E_{\mathrm{rev}}$, in low $\mathrm{Cl}^{-}$, with the average of the current amplitudes in high $\mathrm{Cl}^{-}$ immediately before and after exposure to low $\mathrm{Cl}^{-}$. We specifically chose to report inward currents because this represents the most relevant physiological situation (i.e. $\mathrm{Cl}^{-}$efflux). Using this approach, the calculated percentage stimulation of CFTR activity by external $\mathrm{Cl}^{-}$is independent of any change in driving forces under the low and high $\mathrm{Cl}^{-}$conditions [44]. The pipette (intracellular) solution contained (in $\mathrm{mM}$ ) $139 \mathrm{CsCl}, 2$ $\mathrm{MgCl}_{2}, 5$ ethylene glycol-bis(B-aminoethylether)-N,N,N',N'tetraacetic acid (EGTA), 10 HEPES, 5 glucose, $1 \mathrm{Na}_{2} \mathrm{ATP}$ and $0.1 \mathrm{Na}_{2} \mathrm{GTP}(\mathrm{pH}=7.2$ ) with $\mathrm{CsOH}$. In the experiments using different ATP concentrations or ATP analogues, the $\mathrm{MgCl}_{2}$ concentration was altered to maintain a $1 \mathrm{mM}$ free $\mathrm{Mg}^{2+}$ concentration calculated on a 1:1 basis, with $\mathrm{CsCl}$ concentration adjusted to maintain $\mathrm{Cl}^{-}$concentration and osmolarity. The high-chloride (155.5 mM) bath (extracellular) solution contained (in mM) $145 \mathrm{NaCl}, 4.5 \mathrm{KCl}, 1 \mathrm{MgCl}_{2}, 2 \mathrm{CaCl}_{2}, 10$ HEPES and 15 L-glutamic acid monosodium salt hydrate $(\mathrm{pH}=7.4)$ with $\mathrm{NaOH}$. For the $35.5-\mathrm{mM}$ chloride solution, $120 \mathrm{mM} \mathrm{NaCl}$ was replaced with $120 \mathrm{Na}$ aspartate. Forskolin was purchased from Tocris Bioscience (Bristol, UK) and all other chemicals from Sigma-Aldrich (Poole, UK).

Purification and reconstitution of CFTR The method for purification of CFTR from transfected Sf9 cells using perfluorooctanoate (PFO) has been described previously [15]. The following modification was included. At the point of protein elution from nitrilotriacetic acid beads during fast protein liquid chromatography, the program was interrupted and the protein was subjected to detergent exchange. The column was first washed with $10 \mathrm{ml}$ of a buffer containing $25 \mathrm{mM}$ phosphate, $50 \mathrm{mM} \mathrm{NaCl}, 2 \% \mathrm{PFO}$ at $\mathrm{pH}$ 8.0. A second wash consisted of $50 \mathrm{ml}$ of buffer containing $25 \mathrm{mM}$ HEPES, $100 \mathrm{mM} \mathrm{NaCl}, 1 \mathrm{mM} n$-dodecyl- $\beta$-D-maltopyranoside (DDM) at $\mathrm{pH} 7.4$. The final elution buffer $(25 \mathrm{ml})$ contained $600 \mathrm{mM}$ imidazole. The eluted protein was washed with imidazole-free buffer and concentrated using an Amicon Ultra centrifugal filter device (Milipore Corp. Billerica, MA, USA), (100 kDa cutoff) to bring the imidazole concentration below $1 \mathrm{mM}$ and the protein concentration not greater than $0.2 \mathrm{mg} / \mathrm{ml}$. The protein was phosphorylated at $4{ }^{\circ} \mathrm{C}$ overnight in the presence of $2 \mathrm{mM}$ ATP, $5 \mathrm{mM} \mathrm{Mg}^{2+}$ and $200 \mathrm{nM}$ of protein kinase A catalytic subunit (PKA; Promega Corp. Madison, WI, USA). CFTR was reconstituted into $5 \mathrm{mg}$ of phosphatidyl-ethanolamine (PE):phosphatidylserine (PS):phosphatidylcholine (PC):ergosterol, 5:2:1:1 (w/v) or $5 \mathrm{mg}$ Egg PC by incubation in the presence of DDM and lipid for $30 \mathrm{~min}$, followed by passage through an Extracti-Gel D detergent-binding column (Pierce Corp. Rockford, IL, USA). Purified CFTR was quantitated using an ELISA assay described below and mixed at a ratio of $\sim 1: 1,200$ (protein:lipid, $w / w)$ with Egg PC and DDM.

ATPase assay of purified CFTR The ATPase activity of purified and PKA phosphorylated WT CFTR in DDM micelles was measured as the production of inorganic phosphate in the presence of Na-gluconate/ $\mathrm{NaCl}(100 \mathrm{mM} / 50 \mathrm{mM} \mathrm{NaCl})$ or $\mathrm{NaCl}$ alone $(150 \mathrm{mM})$ with approximately $2 \mu \mathrm{g}$ CFTR protein aliquot per reaction. Three independent purifications of WT CFTR were studied. Phosphate release was determined using the PiPer fluorescent assay (Invitrogen, Burlington, ON, Canada), $1 \mathrm{~h}$ after initiation of the ATPase activity assay by the addition of $0.05-1.0 \mathrm{mM}$ ATP at $37{ }^{\circ} \mathrm{C}$, in the presence of either $\mathrm{Na}$-gluconate/ $\mathrm{NaCl}(100 \mathrm{mM} / 50 \mathrm{mM})$ or $\mathrm{NaCl}$ (150 mM), using approximately $2 \mu \mathrm{g}$ CFTR protein aliquot per reaction. This assay enables the rapid evaluation of 
multiple experimental conditions simultaneously. A caveat of studies of membrane proteins in detergent micelles is the possibility that the detergent environment does not completely recapitulate the interactions conferred by the lipid bilayer on the membrane domains. However, DDM is commonly employed in crystallography studies of the structure of membrane proteins and, more specifically, we found that the ATPase activity of DDM-solubilised CFTR was regulated by PKA-dependent phosphorylation as expected from our previous studies of lipid reconstituted CFTR [31].

Modelling of CFTR A three-dimensional homology model of CFTR was created indicating the relative positions of R899, W401 and E1371 residues (Fig. 1b), based on the work of Dalton et al. [14], using PyMol software (The PyMOL Molecular Graphics System, Version 1.1 eval Schrödinger, LLC)

Statistics Data are presented as mean \pm SEM. Significance of difference between mean values of different constructs was tested either by one-way ANOVA with Bonferroni's Multiple Comparison Test or Kruskal-Wallis followed with Dunn's Multiple Comparison test if Anderson-Darling normality testing of the data showed the values were not normally distributed.

\section{Results}

Role of ECL residues in the gating of CFTR by extracellular $\mathrm{Cl}^{-}$concentration

To establish if CFTR was itself an extracellular $\mathrm{Cl}^{-}$sensor, the positively charged residues in the ECLs of CFTR (R104, K114, R117, K329, K892, R899, R1128) (Fig. 1a), as well as R334 and K335 located at the putative outer mouth of the channel pore [19] (Fig. 1a), were individually mutated to neutral amino acids and the mutant channels tested for their ability to respond to changes in $\left[\mathrm{Cl}^{-}\right]_{\mathrm{o}}$. Note that our previous work found that gating of CFTR by $\left[\mathrm{Cl}^{-}\right]_{\mathrm{o}}$ was voltageindependent [44], and therefore unlikely to involve residues further within the channel pore that experience the transmembrane electric field. Figure 2a illustrates the response of cAMP-activated WT CFTR (cAMP levels increased by FSK) to an increase in $\left[\mathrm{Cl}^{-}\right]_{\mathrm{o}}$ from 35.5 to $155.5 \mathrm{mM}$, which stimulated whole cell currents by $66.1 \pm 13.7 \%(n=24)$, as we have previously reported [44]. Figure $2 b$, c shows that removing the positive charge at position 899 (R899Q) completely abolished $\left[\mathrm{Cl}^{-}\right]_{\mathrm{o}}$ sensing by CFTR (high $\mathrm{Cl}^{-}$stimulation; $4.3 \pm$ $6.6 \%, n=7$ ), whereas all the other ECL charge neutralising mutants had no significant effect on the response (Fig. 2c). Furthermore, introducing a lysine residue in place of arginine (R899K) maintained the response to $\left[\mathrm{Cl}^{-}\right]_{\mathrm{o}}$ (Fig. 2c) while mutating R899 to the negatively charged glutamic acid (R899E) did not, clearly showing that the positive charge at position 899 in ECL4 of CFTR is essential for $\left[\mathrm{Cl}^{-}\right]_{\mathrm{o}}$ sensing. Typical I-V plots obtained in this series of experiments for WT, R899Q and the vector control are shown in Fig. 2b. The effect of FSK on the CFTR currents and the $E_{\text {rev }}$ shifts on switching to low $\left[\mathrm{Cl}^{-}\right]_{\mathrm{o}}$ (an indication of the $\mathrm{Cl}^{-}$selectivity of the FSK-activated currents) for a number of different CFTR constructs and experimental conditions are summarised in Table 1.

Role of ATP hydrolysis and phosphorylation in $\left[\mathrm{Cl}^{-}\right]_{\mathrm{o}}$ gating of CFTR

We next investigated how changes in $\left[\mathrm{Cl}^{-}\right]_{\mathrm{o}}$ were transduced into a change in CFTR activity. Because gating of phosphorylated CFTR is regulated by rounds of ATP binding and hydrolysis at the two NBDs [36, 16, 23], we first focussed on the role of ATP hydrolysis. Non-hydrolysable ATP analogues are known to 'lock' PKA phosphorylated CFTR into the open state upon binding to ATP binding site 2 on NBD2 (the site where rapid ATP hydrolysis normally occurs) [36, $16]$. We first tested the effect of adding $1 \mathrm{mM}$ adenosine $5^{\prime}$-( $\beta, \gamma$-imido)triphosphate lithium salt hydrate (AMP-PNP) to the intracellular (pipette) solution, in the presence of $1 \mathrm{mM}$ ATP, with total $\mathrm{MgCl}_{2}$ increased to $3 \mathrm{mM}$, on WT channel responses. Note that increasing the pipette $\mathrm{MgCl}_{2}$ to $3 \mathrm{mM}$ on its own had no significant effect on the degree of stimulation by $\left[\mathrm{Cl}^{-}\right]_{\mathrm{o}}$ (high $\mathrm{Cl}^{-}$stimulation; $56.7 \pm 8.9 \%, n=7$ ). We confirmed that AMP-PNP was capable of locking open CFTR under these conditions because the rate of current decay following removal of FSK was markedly extended in the presence of AMP-PNP (Fig. 3a). Figure 3b, c and f show that AMP-PNP eliminated the $\left[\mathrm{Cl}^{-}\right]_{\mathrm{o}}$-dependent activation of FSK-stimulated WT CFTR (high $\mathrm{Cl}^{-}$stimulation; $-1.7 \pm$ $3.7 \%, n=5$ ).

We then examined whether the ATP hydrolysis-deficient CFTR mutant, E1371Q [38], could sense $\left[\mathrm{Cl}^{-}\right]_{\mathrm{o}}$ with the expectation that it would not. Like WT CFTR exposed to AMP-PNP, the E1371Q mutant channels display extended open channel bursts in the presence of ATP [16, 23, 40]. In our experiments, E1371Q CFTR expressed in HEK cells was constitutively active and large currents were detected without prior stimulation with FSK (Fig. 3d (i) (first set of fWCR current traces), and 3e), which agrees with previous work performed in baby hamster kidney (BHK) cells [27, 42, 46]. The reason for this constitutive activity of E1371Q is unclear and it contrasts with the behaviour of wild type CFTR and other mutants (except DeltaR-CFTR) previously investigated in our laboratories using the BHK and HEK cell expression systems [46]. Exposing E1371Q CFTR (without FSK) to an increase in $\left[\mathrm{Cl}^{-}\right]_{\mathrm{o}}$ caused only a small stimulation of channel activity (21.9 $\pm 14.1 \%, n=6$; Fig. 3f). Surprisingly in view of 

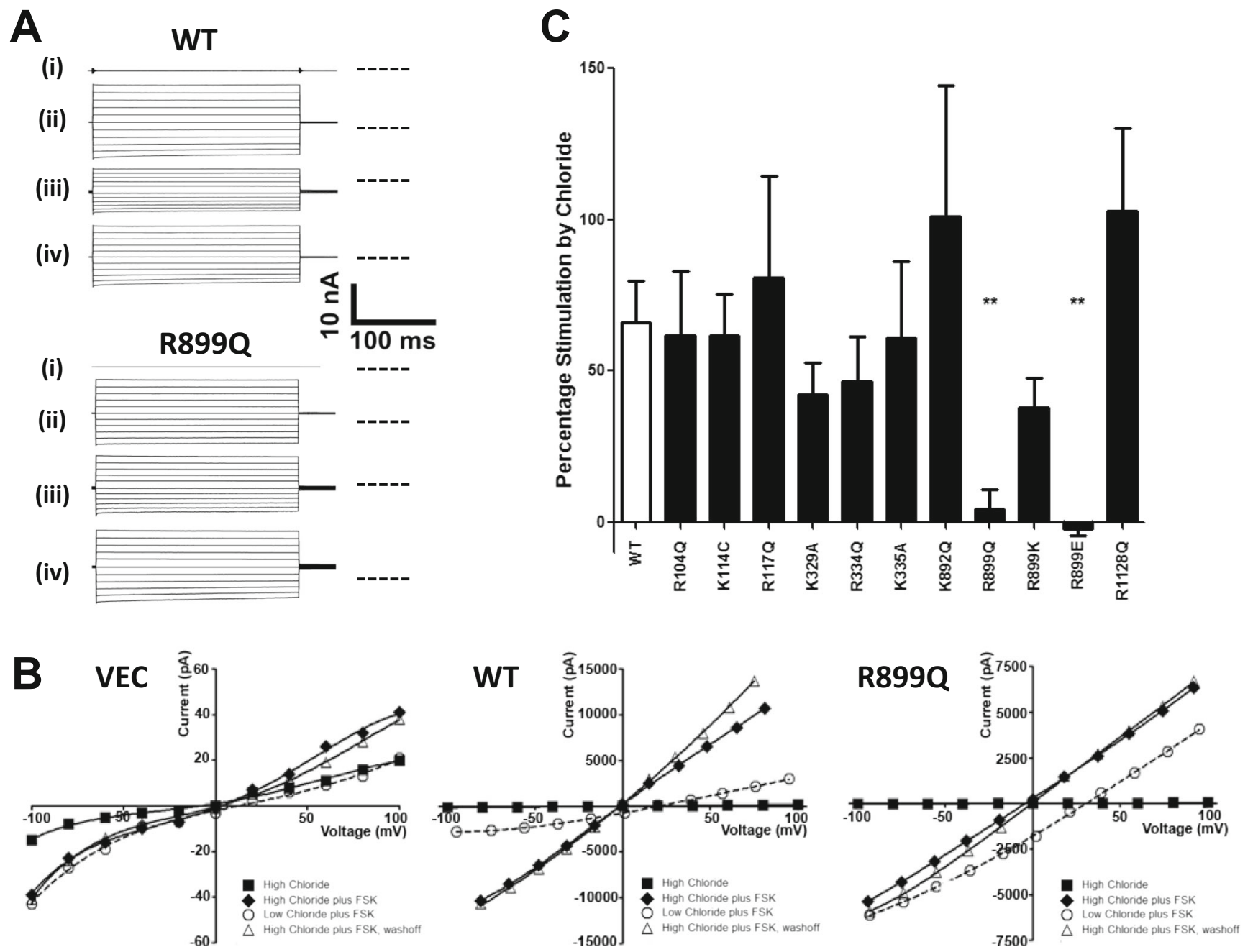

Fig. 2 Arginine residue 889 in extracellular loop 4 of CFTR is essential for $\left[\mathrm{Cl}^{-}\right]_{\mathrm{o}}$ sensing. a Representative fWCR current recordings measured between $\pm 100 \mathrm{mV}$ in $20 \mathrm{mV}$ steps from HEK cells transfected with wild type (WT) CFTR and R899Q CFTR, as indicated. The current traces are

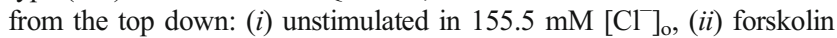
(FSK)-stimulated in $\left.155.5 \mathrm{mM} \mathrm{[Cl}^{-}\right]_{\mathrm{o}}$, (iii) FSK-stimulated in $35.5 \mathrm{mM}$ $\left[\mathrm{Cl}^{-}\right]_{\mathrm{o}}$ and (iv) FSK-stimulated in $155.5 \mathrm{mM}\left[\mathrm{Cl}^{-}\right]_{\mathrm{o}}$. Dotted line to the right of the current traces indicates zero current level. b Representative IV plots for the Vector Control (VEC), WT and R899Q CFTR, for

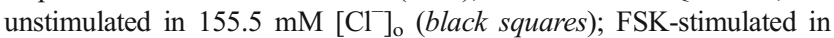

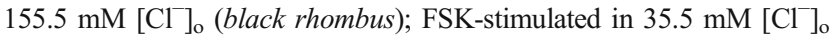

(white circles) and FSK-stimulated in $155.5 \mathrm{mM}\left[\mathrm{Cl}^{-}\right]_{\mathrm{o}}$ washoff (white triangles). I-V plots were obtained from whole cell currents in a. All constructs, except the vector control, showed positive $E_{\text {rev }}$ shifts (see Table 1) on switching to low $\left[\mathrm{Cl}^{-}\right]_{\mathrm{o}}$ consistent with the expression of a $\mathrm{Cl}^{-}$-selective conductance. Note the different $y$-axis scales for the respective I-Vs. $\mathbf{c}$ Percentage stimulation of FSK-activated currents by $\left[\mathrm{Cl}^{-}\right]_{\mathrm{o}}$ for WT CFTR $(n=24)$ and for different extracellular loop mutants (see Fig. 1a) $(n=4-9)$. Percent stimulation was calculated from I-V data at $-60 \mathrm{mV}$ from the reversal potential, as described in "Materials and methods." Data are means \pm SEM. ${ }^{* *} p<0.01$ compared to WT CFTR

the WT CFTR data with AMP-PNP, if E1371Q CFTR channels were first phosphorylated with FSK (which itself had no significant effect on the size of the whole cell currents (Fig. 3d (ii) (second set of fWCR traces)) and Table 1), $\left[\mathrm{Cl}^{-}\right]_{\mathrm{o}}$ sensing was restored $(174.5 \pm 56.2 \%$ stimulation, $n=8$; Fig. $3 \mathrm{~d}$, e and f).

To confirm the role of phosphorylation in $\left[\mathrm{Cl}^{-}\right]_{\mathrm{o}}$ sensing, we reduced the endogenous phosphorylation of E1371Q channels by removing ATP/GTP from the intracellular solution prior to stimulation with FSK, which significantly reduced basal E1371Q CFTR currents (No ATP/GTP: $-186 \pm$ $122 \mathrm{pA} / \mathrm{pF} n=8$ vs ATP/GTP: $-1,259 \pm 433 \mathrm{pA} / \mathrm{pF}, n=8$,
$P<0.001)$. Under these conditions, the E1371Q CFTR channels failed to respond to changes in $\left[\mathrm{Cl}^{-}\right]_{\mathrm{o}}$ even in the presence of FSK (Fig. 3f), consistent with the idea that only phosphorylated channels are gated by $\left[\mathrm{Cl}^{-}\right]_{\mathrm{o}}$. Since E1371Q CFTR is hydrolysis-deficient [38], we expected that $\left[\mathrm{Cl}^{-}\right]_{\mathrm{o}}$ sensing by the mutant would not be affected by AMP-PNP. However, unexpectedly, we found that the ability of FSK-stimulated E1371Q CFTR channels to respond to changes in $\left[\mathrm{Cl}^{-}\right]_{\mathrm{o}}$ was markedly reduced by the non-hydrolysable ATP analogue, just like WT CFTR (Fig. 3f).

To check that the restoration of $\left[\mathrm{Cl}^{-}\right]_{\mathrm{o}}$ sensing by E1371Q CFTR after phosphorylation (Fig. 3d) was due to an 
Table 1 Summary of the FSK stimulation of whole cell currents and $E_{\text {rev }}$ shifts observed with the CFTR constructs used in this study

\begin{tabular}{|c|c|c|c|}
\hline CFTR Construct & $n$ & FSK Stimulation $(\% \pm$ SEM $)$ & Erev shift $(\mathrm{mV} \pm \mathrm{SEM})$ \\
\hline WT (50 $\mu \mathrm{M}$ ATP $)$ & 5 & $180 \pm 96$ & $15.0 \pm 3.6$ \\
\hline WT (100 $\mu \mathrm{M}$ ATP $)$ & 6 & $12,000 \pm 6,000$ & $15.2 \pm 3.0$ \\
\hline WT (300 $\mu \mathrm{M}$ ATP) & 8 & $1,200 \pm 600$ & $17.0 \pm 3.0$ \\
\hline WT (1 mM ATP) & 24 & $13,000 \pm 6,000$ & $23.7 \pm 1.8$ \\
\hline WT (1.3 mM ATP) & 9 & $1,400 \pm 900$ & $16.7 \pm 2.6$ \\
\hline WT (2 mM ATP) & 24 & $6,100 \pm 5,300$ & $16.7 \pm 1.6$ \\
\hline WT (5 mM ATP) & 7 & $1,600 \pm 1,000$ & $20.1 \pm 4.4$ \\
\hline $\mathrm{WT}(50 \mu \mathrm{M}$ ATP $+50 \mu \mathrm{M}$ P-ATP $)$ & 7 & $224 \pm 130$ & $15.3 \pm 1.0$ \\
\hline WT + Genistein & 4 & $7,600 \pm 5,200$ & $26.1 \pm 5.4$ \\
\hline WT + AMP-PNP & 5 & $2,800 \pm 2,500$ & $21.8 \pm 5.5$ \\
\hline WT (3 mM MgCl 2$)$ & 7 & $28,000 \pm 17,000$ & $18.3 \pm 3.1$ \\
\hline R104Q & 5 & $4,600 \pm 1,600$ & $28.6 \pm 4.7$ \\
\hline K114C & 5 & $12,000 \pm 6,700$ & $29.2 \pm 3.0$ \\
\hline R117Q & 4 & $33,000 \pm 20,000$ & $30.1 \pm 3.4$ \\
\hline K329A & 5 & $13,000 \pm 10,000$ & $33.7 \pm 2.1$ \\
\hline R334Q & 9 & $13,000 \pm 6,700$ & $27.3 \pm 2.9$ \\
\hline K335A & 5 & $3,200 \pm 1,500$ & $20.8 \pm 7.1$ \\
\hline W401G & 7 & $2,600 \pm 1,800$ & $18.5 \pm 4.8$ \\
\hline Delta-R (No Stim) & 5 & - & $25.1 \pm 2.7$ \\
\hline Delta-R (No FSK, Genistein) & 5 & $140 \pm 13$ & $22.7 \pm 3.0$ \\
\hline Delta-R (FSK, No Genistein) & 4 & $89 \pm 14$ & $15.6 \pm 6.0$ \\
\hline Delta-R (FSK + Genistein) & 6 & $639 \pm 432$ & $25.1 \pm 4.9$ \\
\hline Delta-R-E1371S (No FSK) & 9 & - & $21.4 \pm 4.8$ \\
\hline Delta-R-E1371S (FSK) & 4 & $2,600 \pm 1,400$ & $15.3 \pm 4.7$ \\
\hline K892Q & 7 & $16,000 \pm 9,500$ & $36.8 \pm 4.8$ \\
\hline R899E & 4 & $1,200 \pm 400$ & $25.0 \pm 2.7$ \\
\hline R899K & 4 & $1,600 \pm 900$ & $26.6 \pm 2.9$ \\
\hline R899Q & 7 & $5,400 \pm 2,800$ & $30.0 \pm 1.3$ \\
\hline R899Q + AMP-PNP & 4 & $72,000 \pm 50,000$ & $15.2 \pm 2.8$ \\
\hline R899Q-E1371Q (No FSK) & 4 & - & $18.4 \pm 5.9$ \\
\hline R899Q-E1371Q (FSK) & 6 & $107 \pm 48$ & $15.6 \pm 3.0$ \\
\hline R1128Q & 6 & $14,000 \pm 6,100$ & $41.1 \pm 4.2$ \\
\hline Y1219G & 6 & $3,200 \pm 2,500$ & $19.2 \pm 3.3$ \\
\hline E1371Q (No FSK) & 6 & - & $25.5 \pm 3.5$ \\
\hline E1371Q (FSK) & 8 & $-28 \pm 9$ & $22.3 \pm 4.0$ \\
\hline E1371Q (FSK, No ATP, No GTP) & 8 & $270 \pm 130$ & $19.4 \pm 4.5$ \\
\hline E1371Q + AMP-PNP (No FSK) & 4 & - & $24.7 \pm 6.5$ \\
\hline E1371Q + AMP-PNP (FSK) & 8 & $180 \pm 170$ & $17.4 \pm 4.0$ \\
\hline Vector Control & 4 & $15 \pm 38$ & - \\
\hline
\end{tabular}

FSK stimulation was calculated as the percentage increase in current density at $-60 \mathrm{mV}$ from the $E_{\text {rev }}$, after 5-min exposure to $10 \mu \mathrm{M}$ FSK. The $E_{\text {rev }}$ shift is the change in $E_{\mathrm{rev}}$ value on switching from 155.5 to $35.5 \mathrm{mM}\left[\mathrm{Cl}^{-}\right]_{\mathrm{o}}$, in the presence of forskolin (see "Material and methods"). The $E_{\mathrm{rev}}$ shift predicted by the Nernst equation for a perfectly selective $\mathrm{Cl}^{-}$conductance under these conditions is $37.5 \mathrm{mV}$. Note that because the vector control currents were very small (Fig. 2b), the $E_{\text {rev }}$ shift is unreliable and not included in the Table

interaction of $\mathrm{Cl}^{-}$with the extracellular domain of CFTR, we also studied the double-mutant R899Q-E1371Q. Figure 3f shows that $\left[\mathrm{Cl}^{-}\right]_{\mathrm{o}}$ sensing by the double mutant in the presence of FSK was significantly reduced compared to E1371Q CFTR under the same conditions, confirming that phosphorylated
E1371Q CFTR channels respond to changes in $\left[\mathrm{Cl}^{-}\right]_{\mathrm{o}}$ via R899 in ECL4.

To explore the role of phosphorylation further, we studied the effect of deleting the R domain from CFTR (residues 634 836) $[12,7]$, which removes all the major PKA/PKC 


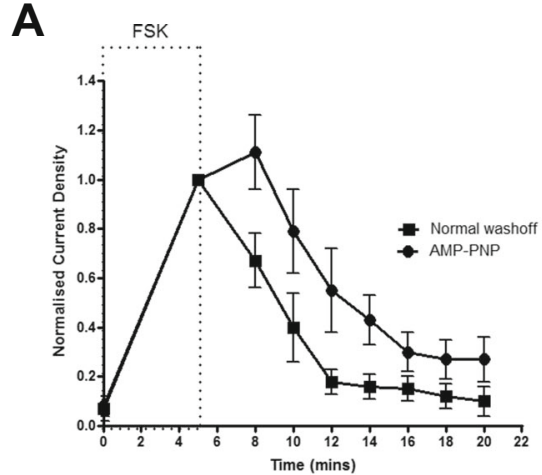

D

\section{E1371Q (FSK)}

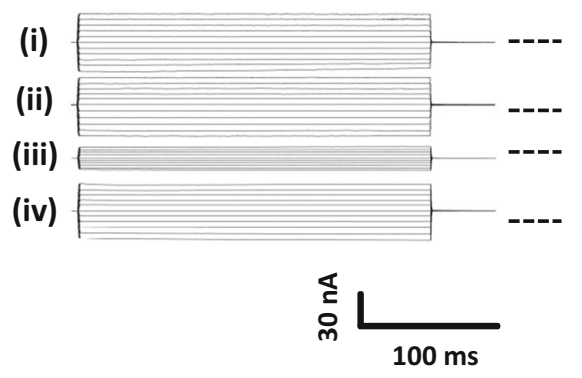

B
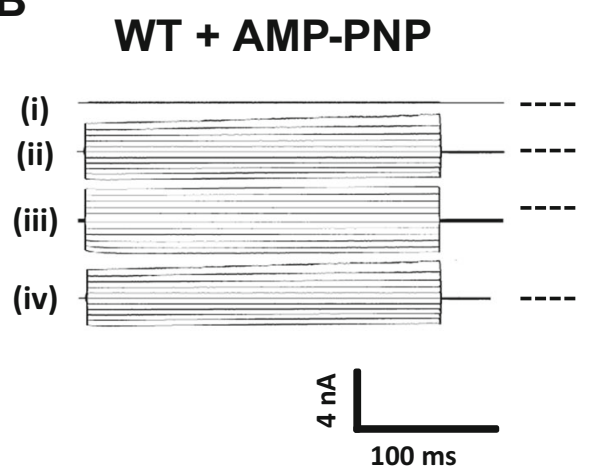

C WT + AMP-PNP

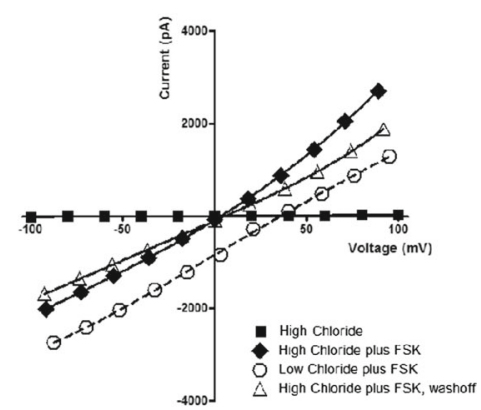

E

\section{E1371Q (FSK)}

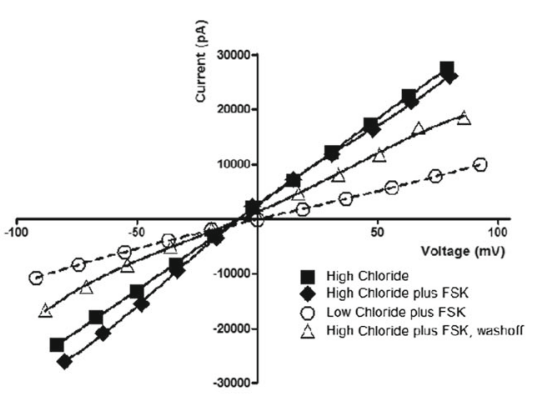

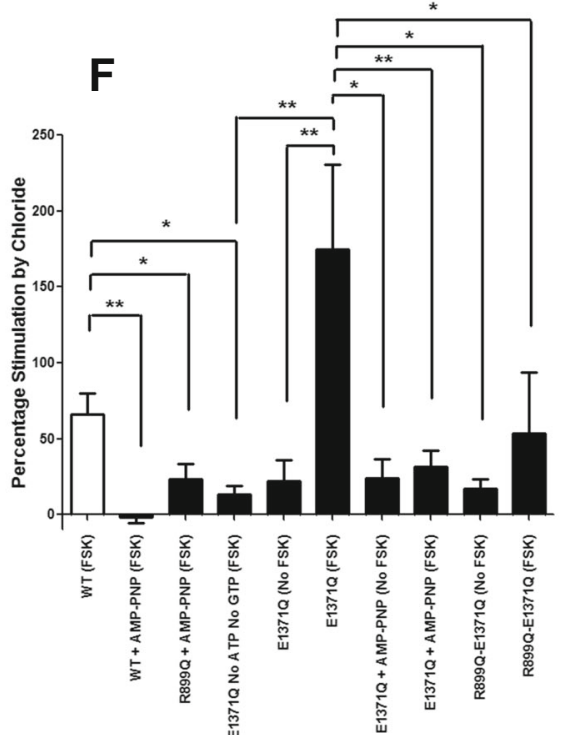

Fig. 3 Gating of CFTR by $\left[\mathrm{Cl}^{-}\right]_{\text {o }}$ requires ATP hydrolysis and phosphorylation. a AMP-PNP locks WT CFTR in the open state. Normalised whole cell current density is plotted against time during FSK stimulation (indicated by the dashed line) and the subsequent washoff in the absence (squares, $n=4$ ) and presence (circles, $n=4$ ) of $1 \mathrm{mM}$ AMP-PNP in the pipette solution. b, $\mathbf{d}$ Representative fWCR current recordings measured between $\pm 100 \mathrm{mV}$ in $20 \mathrm{mV}$ steps from HEK cells transfected with WT CFTR plus AMP-PNP and E1371Q CFTR, as indicated. The current

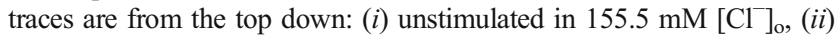

consensus phosphorylation sites [36, 32]. Unlike WT CFTR, DeltaR-CFTR channels are spontaneously active without PKA phosphorylation, but are gated normally by cytosolic ATP [12, 7]. Note that because this mutant does not express very well in HEK cells, we also included $30 \mu \mathrm{M}$ genistein (a CFTR potentiator, [1]) with FSK to increase the activity of DeltaR-CFTR channels. Genistein itself had no effect on the ability of DeltaRCFTR (nor WT CFTR) to respond to changes in $\left[\mathrm{Cl}^{-}\right]_{\mathrm{o}}$ (data not shown), so the FSK and genistein results have been combined. Figure $4 \mathrm{a}-\mathrm{e}$ shows that both in the absence and presence of stimulants (FSK + Genistein), DeltaR-CFTR exhibited WTlike levels of $\left[\mathrm{Cl}^{-}\right]_{\mathrm{o}}$ stimulation, indicating that deleting the $\mathrm{R}$ domain removes the phosphorylation-dependence of $\left[\mathrm{Cl}^{-}\right]$o sensing observed for WT CFTR (Fig. 2). Based on our previous result that the phosphorylated, hydrolysis-deficient, E1371Q forskolin (FSK)-stimulated in $\left.155.5 \mathrm{mM} \mathrm{[ \textrm {Cl } ^ { - }}\right]_{\mathrm{o}}$, (iii) FSK-stimulated in $35.5 \mathrm{mM}\left[\mathrm{Cl}^{-}\right]_{\mathrm{o}}$ and (iv) FSK-stimulated in $155.5 \mathrm{mM}\left[\mathrm{Cl}^{-}\right]_{\mathrm{o}}$. Dotted line to the right of the current traces indicates zero current level. c, e Representative I-V plots for the data presented in $\mathbf{b}$ and $\mathbf{d}$. $\mathbf{f}$ Percentage stimulation of either basal or FSK-activated currents by $\left[\mathrm{Cl}^{-}\right]_{\mathrm{o}}$ for WT CFTR ( $n=24)$, the ECL4 mutant R899Q, the hydrolysis-deficient mutant E1371Q and the double-mutant R899Q-E1371Q (see Fig. 1) under different conditions as indicated $(n=4-8)$. Data are means \pm SEM. ${ }^{*} p<0.05,{ }^{*} p<0.01, * * * p<0.001$ between indicated datasets

mutant could sense $\left[\mathrm{Cl}^{-}\right]_{\mathrm{o}}$ (Fig. 3f), we predicted that preventing ATP hydrolysis at ATP binding site 2 of DeltaRCFTR would have no effect on $\left[\mathrm{Cl}^{-}\right]_{\mathrm{o}}$ sensing. We tested this prediction by using DeltaR-CFTR with the E1371S mutation, which like E1371Q CFTR is hydrolysis defective [8] and found, unexpectedly, that the double-mutant CFTR channels did not respond to changes in $\left[\mathrm{Cl}^{-}\right]_{\mathrm{o}}$ (external $\mathrm{Cl}^{-}$stimulation; no FSK/genistein: $0.0 \pm 7.0 \%, n=9$; with FSK/genistein: $16.7 \pm$ $7.7 \%, n=4$ ) (Fig. $4 \mathrm{c}-\mathrm{e}$ ).

Role of ATP binding and ATPase activity of the NBDs in $\left[\mathrm{Cl}^{-}\right]_{\mathrm{o}}$ sensing by CFTR

Figures 3 and 4 suggest that the role of ATP hydrolysis in $\left[\mathrm{Cl}^{-}\right]_{\mathrm{o}}$ sensing by CFTR is complex; e.g. AMP-PNP abolishes 
A

DeltaR (No Stim)

(i)

(ii)

(iii)
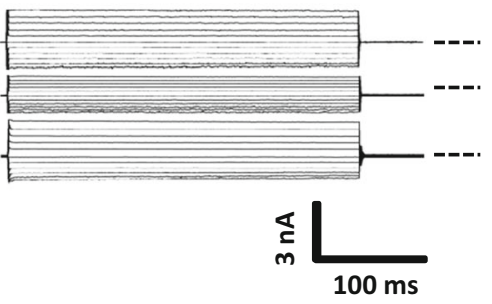

C

\section{DeltaR-E1371S (No Stim)}

(i)

(ii)
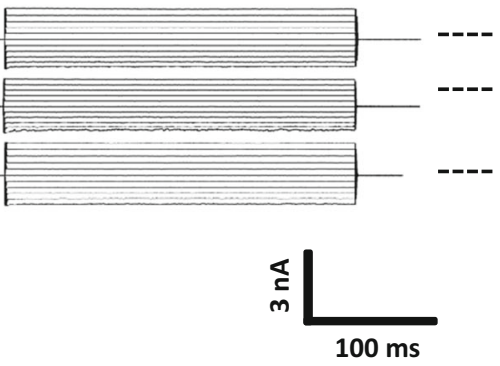

B

\section{DeltaR (No Stim)}

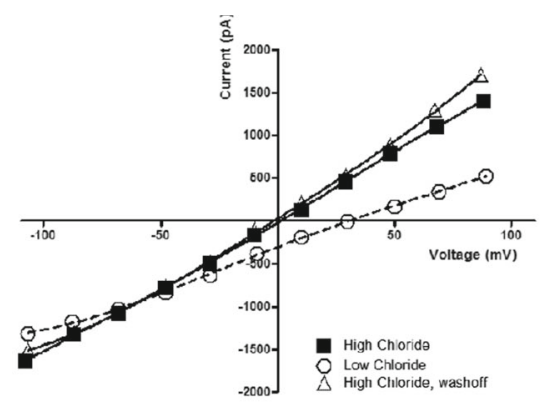

D
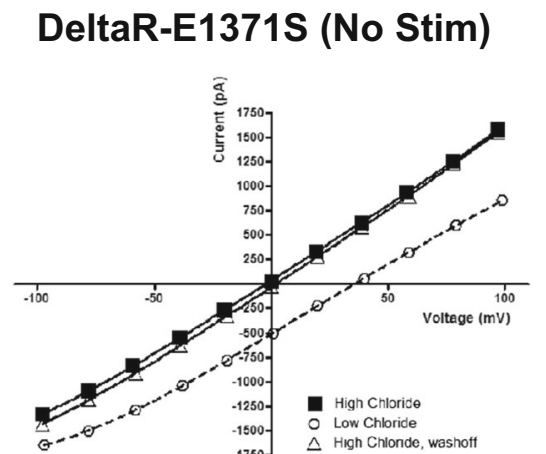

E

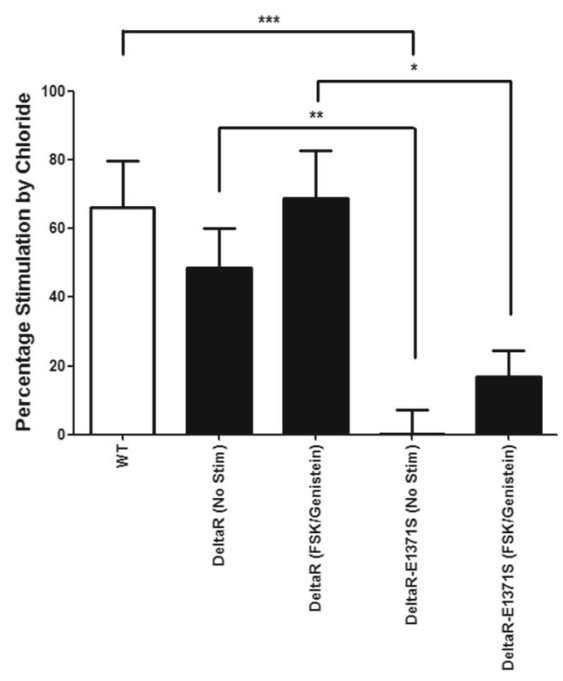

Fig. 4 Role of the R domain in $\left[\mathrm{Cl}^{-}\right]_{\mathrm{o}}$ sensing by CFTR. a, $\mathbf{c}$ Representative fWCR current recordings measured between $\pm 100 \mathrm{mV}$ in $20 \mathrm{mV}$ steps from HEK cells transfected with deltaR-CFTR or deltaR-E1371S CFTR as indicated. Note all experiments used unstimulated conditions. The current traces are from the top down: (i) unstimulated in $155.5 \mathrm{mM}$ $\left[\mathrm{Cl}^{-}\right]_{\mathrm{o}}$, (ii) unstimulated in $\left.35.5 \mathrm{mM} \mathrm{Cl}^{-}\right]_{\mathrm{o}}$ and (iii) unstimulated in $155.5 \mathrm{mM}\left[\mathrm{Cl}^{-}\right]_{\text {o }}$. Dotted line to the right of the current traces indicates

$\left[\mathrm{Cl}^{-}\right]_{\mathrm{o}}$ sensing by WT CFTR, whereas the E1371Q mutation has no effect. Possibly changes in ATP interaction with the NBDs, and/or subsequent NBD dimerisation, rather than just hydrolysis, could be primarily responsible for the effects of $\left[\mathrm{Cl}^{-}\right]_{\mathrm{o}}$. To test this idea, we individually mutated key residues involved in ATP binding at site 1 in NBD1 (W401) and site 2 in NBD2 (Y1219) to glycine (Fig. 1), and then measured responses to changes in $\left[\mathrm{Cl}^{-}\right]_{\mathrm{o}}$. Note that both of these mutations substantially reduce CFTR channel activity through mechanisms that are not secondary to changes in ATP hydrolysis rate [49], and in the case of W401G, not due to an apparent change in ATP binding affinity. Sub-panels a, b and e of Fig. 5 show that the FSK-stimulated W401G CFTR mutant exhibited significantly reduced $\left[\mathrm{Cl}^{-}\right]_{\mathrm{o}}$ sensing compared to WT CFTR, whereas the FSK-stimulated Y1219G CFTR mutant did not (Fig. 5c-e).

We then reasoned that if events downstream of ATP binding to site 1 , and/or NBD dimerisation, were altered by changes in $\left[\mathrm{Cl}^{-}\right]_{\mathrm{o}}$ (as the W401G data suggested), then the effect of $\left[\mathrm{Cl}^{-}\right]_{\mathrm{o}}$ on CFTR activity should be sensitive to the concentration of cytosolic ATP. Figure $5 \mathrm{f}$ shows that this was indeed the zero current level. b, $\mathbf{d}$ Representative I-V plots for the data presented in a and c. e Percentage current stimulation by $\left[\mathrm{Cl}^{-}\right]_{\mathrm{o}}$ for WT CFTR $(n=24)$ and for DeltaR and DeltaR-E1371Q mutants (see Fig. 1) under unstimulated (No Stim) or after exposure to a combination of forskolin and genistein (FSK/Genistein). $(n=4-10)$. Data are means \pm SEM. ${ }^{*} p<0.05,{ }^{*} p<0.01$ compared to indicated datasets

case. $\left[\mathrm{Cl}^{-}\right]_{\mathrm{o}}$ sensing by CFTR was gradually abolished as cytosolic [ATP] was increased to $\sim 2 \mathrm{mM}$, with an estimated $\mathrm{IC}_{50}$ of $1.15 \pm 0.14 \mathrm{mM}$, and a maximal stimulation of $80.0 \pm$ $11.3 \%$. Consistent with the idea that ATP binding energy and/ or NBD dimerisation was being altered by $\left[\mathrm{Cl}^{-}\right]_{\mathrm{o}}$, we also investigated the effect of including a higher affinity ATP analogue, $\mathrm{N}^{6}$-(2-phenylethyl)-ATP (P-ATP, [48]), with a low dose of ATP $(50 \mu \mathrm{M})$. The presence of P-ATP $(50 \mu \mathrm{M})$ significantly reduced the ability of WT CFTR to respond to changes in $\left[\mathrm{Cl}^{-}\right]_{\text {o }}$ when compared to the equivalent control (100 $\mu \mathrm{M}$ ATP) response (Fig. 5f, open circle), further implicating ATP/NBD interaction as a key factor in the activation of CFTR by high $\left[\mathrm{Cl}^{-}\right]_{\mathrm{o}}$.

If high $\left[\mathrm{Cl}^{-}\right]_{\mathrm{o}}$ activates CFTR by stabilising the NBD1NBD2 dimer, as suggested by the results in Fig. 5, we reasoned that the ATPase activity of WT CFTR (which is mostly conferred by site $2 ;[38,6]$ ) should be reduced by high $\left[\mathrm{Cl}^{-}\right]$. To test this prediction, we performed ATPase measurements on purified CFTR reconstituted into micelles and prephosphorylated by PKA as previously described [15], over a range of $[\mathrm{ATP}]$. Figure 6 shows that when total $\left[\mathrm{Cl}^{-}\right]$was 

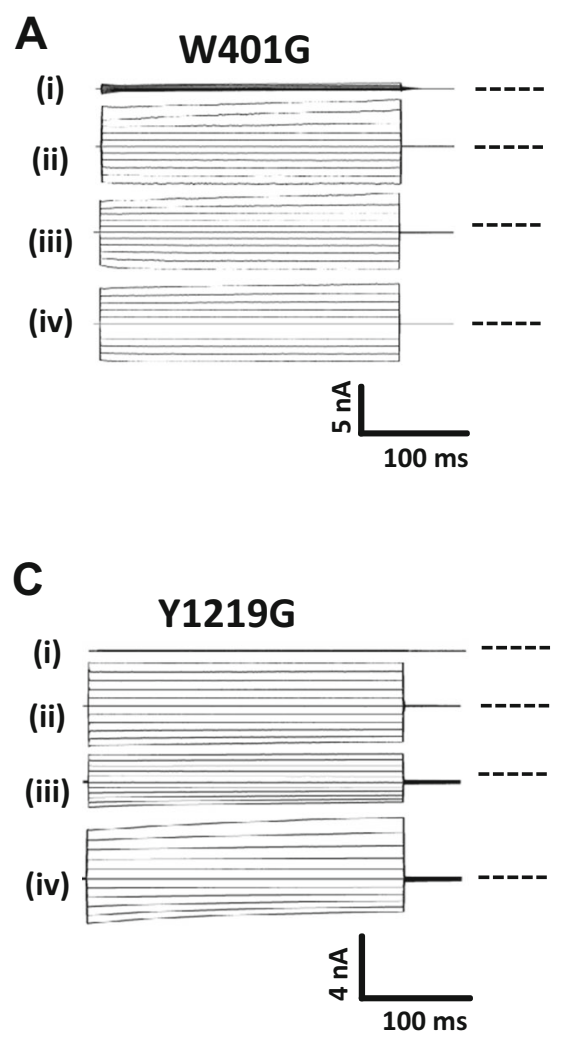

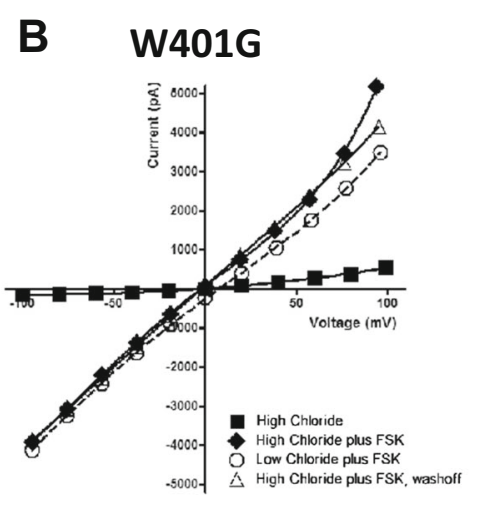

D

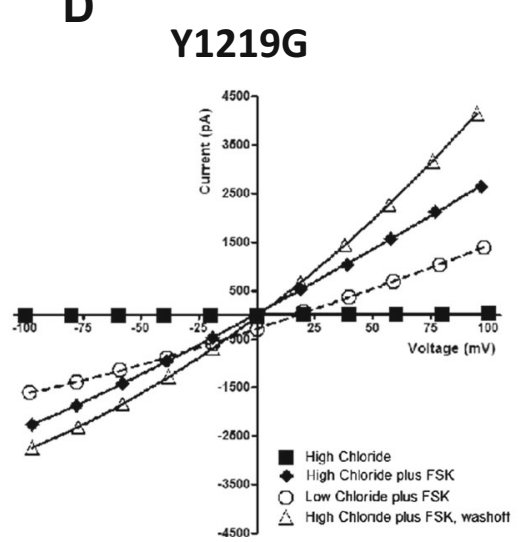

E
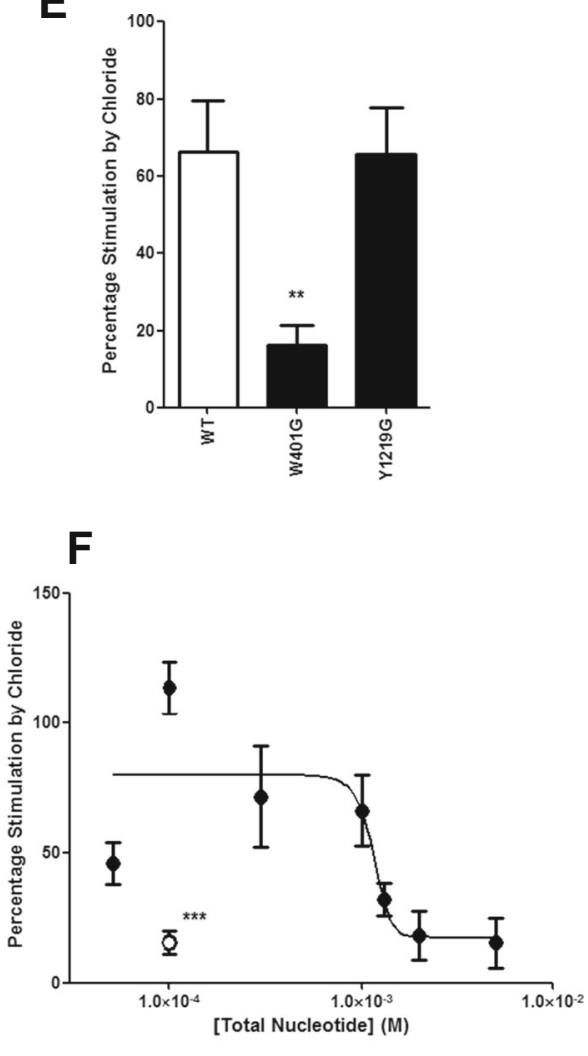

Fig. 5 ATP binding to site 1, but not site 2, underlies $\left[\mathrm{Cl}^{-}\right]_{\mathrm{o}}$ sensing by CFTR. a, c Representative fWCR current recordings measured between $\pm 100 \mathrm{mV}$ in $20 \mathrm{mV}$ steps from HEK cells transfected with W401G CFTR or Y1219G CFTR, as indicated. The current traces are from the top down: (i) unstimulated in $155.5 \mathrm{mM}\left[\mathrm{Cl}^{-}\right]_{\mathrm{o}}$, (ii) forskolin (FSK)-stimulated in

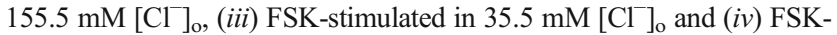
stimulated in $155.5 \mathrm{mM}\left[\mathrm{Cl}^{-}\right]_{\mathrm{o}}$. Dotted line to the right of the current traces indicates zero current level. $\mathbf{b}$, $\mathbf{d}$ Representative I-V plots for the data presented in a and c. e Percentage current stimulation by $\left[\mathrm{Cl}^{-}\right]_{\mathrm{o}}$ for

increased from 50 to $150 \mathrm{mM}$ (with total salt kept constant at $150 \mathrm{mM}$ using Na-gluconate as a replacement for $\mathrm{NaCl}$ ), there

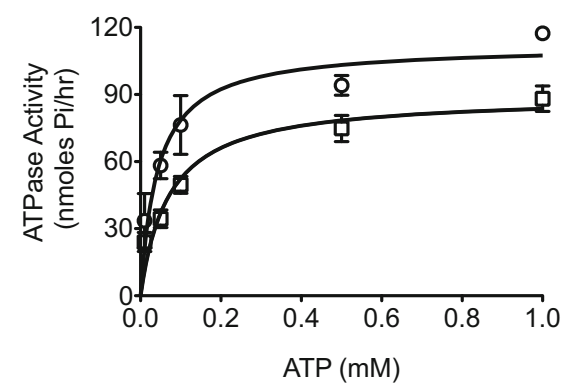

Fig. 6 ATPase activity of CFTR is stimulated by a decrease in $\mathrm{Cl}^{-}$ concentration. Purified WT CFTR was reconstituted into dodecylmaltoside (DDM) micelles in the presence of either $150 \mathrm{mM}$ (squares) or $50 \mathrm{mM} \mathrm{Cl}^{-}$(circles) and the ATPase activity measured over a range of ATP concentrations, as described in the "Materials and methods." Data are means \pm SEM for 3 (low $\mathrm{Cl}^{-}$) or 4 (high $\mathrm{Cl}^{-}$) separate purification/reconstitution experiments. Data points fitted using the Michaelis Menten equation $\left(r^{2}=0.83(\mathrm{NaCl})\right.$ and $\left.r^{2}=0.8(\mathrm{NaGlu})\right)$
WT CFTR $(n=24)$ and for W401G (NBD1) and Y1219G (NBD2) mutants (see Fig. 1) $(n=7-8)$. Data are mean \pm SEM. ${ }^{* *} p<0.01$ compared to WT CFTR. $\mathbf{f}$ Percentage current stimulation by $\left[\mathrm{Cl}^{-}\right]_{\mathrm{o}}$ for WT CFTR at different cytosolic (pipette) ATP concentrations. Data are means \pm SEM $(n=5-24)$. Data points fitted using least squares fit of a $\log$ [inhibition] vs response equation, with variable slope function and with no constraints or weighting. The open circle shows the effect of including $50 \mu \mathrm{M}$ P-ATP with $50 \mu \mathrm{M}$ ATP on the response to $\left[\mathrm{Cl}^{-}\right]_{\mathrm{o}} .{ }^{* * *} p<0.001$ compared to $100 \mu \mathrm{M}$ ATP

was a marked shift in the ATPase activity curve, such that at over the range of [ATP] up to $1.0 \mathrm{mM}$, there was a significant decrease in ATPase activity. This change in ATPase activity was due to a reduction in ATP turnover $\left(V_{\max }\right.$ for low $\left[\mathrm{Cl}^{-}\right]$; $114.3 \pm 1.5 \mathrm{nmol} / \mathrm{h}, n=3$, versus high $\left[\mathrm{Cl}^{-}\right] ; 89.3 \pm 7.3 \mathrm{nmol} / \mathrm{h}$, $n=4, p<0.04$ ), without a significant change in apparent binding affinity $\left(K_{\mathrm{m}}\right)$ of CFTR for ATP $\left(K_{\mathrm{m}}\right.$ for low $\left[\mathrm{Cl}^{-}\right] ; 48 \pm$ $12 \mu \mathrm{M}, n=3$ versus high $\left.\left[\mathrm{Cl}^{-}\right] ; 69 \pm 16 \mu \mathrm{M}, n=4, p>0.05\right)$.

\section{Discussion}

Our data provide the first evidence that $\left[\mathrm{Cl}^{-}\right]_{\mathrm{o}}$-dependent stimulation of CFTR is an intrinsic property of the channel, and that R899 located in ECL4 is absolutely essential for the response. Although neutralization of the positive charge at R899, as well as charge reversal, eliminated $\left[\mathrm{Cl}^{-}\right]_{\mathrm{o}}$ sensing by CFTR (Fig. 2), we have no direct evidence that $\mathrm{Cl}^{-}$ions 
actually bind to this residue. Nevertheless, we assume that R899 must reside somewhere in the pathway between $\mathrm{Cl}^{-}$ binding and enhanced CFTR activity. In support of this conclusion, the stimulating effect of $\left[\mathrm{Cl}^{-}\right]_{\mathrm{o}}$ cannot be due to the ion entering the pore, since mutations that do affect CFTR $\mathrm{Cl}^{-}$ conductance (R104Q, R117Q, R334Q, K335A) have no effect on $\left[\mathrm{Cl}^{-}\right]_{\mathrm{o}}$ stimulation (Fig. 2), and the one site that is important for sensing (R899) does not affect $\mathrm{Cl}^{-}$conductance $[45,47]$. It is conceivable that the $\mathrm{R} 899 \mathrm{Q} / \mathrm{E}$ mutations cause abnormal folding of CFTR, which results in a change in the interaction between $\mathrm{Cl}^{-}$and some other residue in the protein. However, we noticed no major differences in the expression levels of WT CFTR and the R899 mutants, nor any effects of R899 mutations on CFTR channel properties; e.g. cAMP activation, which would be expected if there was a major folding problem $[45,47]$.

We can make a number of conclusions about the molecular mechanism involved in the $\left[\mathrm{Cl}^{-}\right]_{\mathrm{o}}$ stimulation of CFTR. First, cAMP/PKA-dependent phosphorylation is required for the response in WT and E1371Q CFTR channels. However, since $\left[\mathrm{Cl}^{-}\right]_{\mathrm{o}}$ sensing still occurred when the $\mathrm{R}$ domain was deleted (Fig. 4), the ability to respond to $\left[\mathrm{Cl}^{-}\right]_{\mathrm{o}}$ must reside in other domains. In intact CFTR, these are likely to be parts of the protein that are regulated by the $\mathrm{R}$ domain once it is phosphorylated. Although the $\mathrm{R}$ domain is a relatively disordered structure, there is evidence from NMR studies that regions of the R domain interact with the NBDs [4, 9]. Upon phosphorylation of the $\mathrm{R}$ domain, it is thought that these regions of interaction change and that this allows the NBDs to dimerise in the presence of ATP, thereby promoting channel opening $[36,16,23,4,9]$. Therefore, in terms of facilitating $\left[\mathrm{Cl}^{-}\right]_{\mathrm{o}}$ sensing, both phosphorylation of the $\mathrm{R}$ domain and its deletion are functionally equivalent (but see below).

Secondly, in phosphorylated CFTR channels, impairing ATP hydrolysis using the E1371Q mutation did not prevent $\left[\mathrm{Cl}^{-}\right]_{\mathrm{o}}$ sensing. This result implies that chloride sensing does not lead to a change in channel gating simply via a change in ATPase activity. Although chloride sensing does cause a modest change in intrinsic ATPase activity (Fig. 6), this cannot account for the larger effects on channel gating. The fact that $\left[\mathrm{Cl}^{-}\right]_{\mathrm{o}}$ sensing is impaired in phosphorylated E1371Q CFTR channels when AMP-PNP is present, is probably explained by AMP-PNP substituting for ATP in its actions. As Fig. $5 \mathrm{f}$ shows, raising cytosolic [ATP] to $2 \mathrm{mM}$, or above, abolished sensing. This is why AMP-PNP effects are mimicked by ATP, but not by the E1371Q mutation. In this context, it is important to remember that although the E1371Q mutation substantially reduces ATP hydrolysis $(\sim 70 \%,[38])$, the channel is still gated by ATP, even in a DeltaR background $[12,7,8]$. The one caveat to this interpretation is that $\left[\mathrm{Cl}^{-}\right]_{\mathrm{o}}$ sensing by DeltaR-CFTR was abolished when ATP hydrolysis at NBD2 was blocked by the E1371S mutation. This result indicates that intra-domain interactions in CFTR that lacks an R domain cannot fully recapitulate those in WT CFTR, despite evidence that DeltaR-CFTR has similar gating properties to WT CFTR $[12,7]$.

Thirdly, the fact that $\left[\mathrm{Cl}^{-}\right]_{\mathrm{o}}$ sensing is abolished by the W401G mutation in NBD1, but not by the corresponding NBD2 mutant, Y1219G (Fig. 5e), suggests that ATP binding at NBD1, and not NBD2, is mainly responsible for transducing the $\left[\mathrm{Cl}^{-}\right]_{0}$-dependent gating changes. Furthermore, since P-ATP also prevented $\left[\mathrm{Cl}^{-}\right]_{\mathrm{o}}$ from changing CFTR activity (Fig. 5f), then our results are best explained by external $\mathrm{Cl}^{-}$ affecting the stability of the NBD1/NBD2 dimer (more stable at higher external $\mathrm{Cl}^{-}$). Thus both the presence of cytosolic PATP as well high $\left[\mathrm{Cl}^{-}\right]_{\mathrm{o}}$ converge on the same process.

Fourthly, changes in $\mathrm{Cl}^{-}$concentration, at constant $\mathrm{Na}^{+}$, alters the intrinsic ATPase activity of intact CFTR by $\sim 20 \%$, which argues for a direct effect of $\mathrm{Cl}^{-}$on the intrinsic catalytic activity of the protein (Fig. 6). This result shows that in addition to total salt concentration [24], $\mathrm{Cl}^{-}$concentration alone can regulate the ATPase activity of purified CFTR and appears to do this by altering the ATP turnover (hydrolysis) rate by the NBDs. The mechanism for this change in ATP turnover is uncertain at the present time. In addition, whether substitution of arginine for glutamine at position 899 in ECL4 leads to a change in ATPase activity of the CFTR is an important area for future research.

In conclusion, our results support a mechanism whereby an increase in $\left[\mathrm{Cl}^{-}\right]_{\mathrm{o}}$ stimulates CFTR activity by modulating ATP binding/interaction at NBD1, which favours NBD dimerisation, reducing ATP hydrolysis and hence increasing channel activity. Thus our results suggest that the increased $P_{o}$ of the CFTR channel that we reported previously under high $\left[\mathrm{Cl}^{-}\right]_{\mathrm{o}}$ conditions [44] is due to external $\mathrm{Cl}^{-}$acting at ECL4 to alter single channel gating. In addition, and in contrast to the known effects on $\mathrm{P}_{\mathrm{o}}$, an effect of external $\mathrm{Cl}^{-}$on the number of active channels $(\mathrm{N})$ and the single channel current (i) can effectively be ruled out. Thus the current paradigm that transmission of 'gating information' in phosphorylated CFTR is temporally and spatially directed from the cytosolic NBDs to the TMDs needs to be revised. Specifically, our data shows that an interaction of $\mathrm{Cl}^{-}$with externally accessible parts of the TMDs also feeds back to modulate NBD function. How R899 in ECL4 alters CFTR gating is unclear; however, ECL4 connects transmembrane segments 7 and 8 in TMD2 and is the largest ECL in CFTR and exhibits considerable flexibility (Fig. 1b). Recent molecular modelling and cross-linking experiments $[21,28,34]$ predict that there are inter-domain interactions between the TMDs and their opposite NBDs through the intracellular loops (ICLs), which act as coupling helices. Since TM segment 8 is connected to TM segment 9 via ICL3, and ICL3 has been shown to lie in close proximity to NBD1, and to interact with the NBD-ATP binding sites [28], then it is conceivable that $\mathrm{Cl}^{-}$-dependent alterations in ECL4 are transmitted to NBD1 via ICL3. 
Altogether, our present results, together with previous studies $[30,20]$, demonstrate that the short ECLs of CFTR are important for controlling channel activity. However, this study is the first to provide an explanation for how an ECL residue can alter CFTR gating via changes in the interaction of cytosolic ATP with CFTR NBDs. Interestingly, a recent study by Cui et al. [13] has shown that three charged amino acid residues in ECL1 (D110, E116 and R117) are involved in stabilising the architecture of the outer pore of CFTR by interacting with other charged residues, including K892 in ECL4. Furthermore, our lab has recently demonstrated, through cross-linking of residues in ECL1 and ECL4, that the relative movement of these two ECLs is necessary for normal channel gating [10] which further demonstrates the important role of the ECLs in CFTR channel function.

We speculate that $\left[\mathrm{Cl}^{-}\right]_{\mathrm{o}}$ sensing may be a feedback mechanism allowing CFTR to orchestrate anion and fluid secretion in epithelial tissues that secrete an isotonic mixture of $\mathrm{Cl}^{-}$and $\mathrm{HCO}_{3}{ }^{-}[25,33,37,39,43]$. For instance, in pancreatic ducts, luminal $\left[\mathrm{Cl}^{-}\right]$falls as luminal $\left[\mathrm{HCO}_{3}{ }^{-}\right]$rises which would limit CFTR activity and favour hyperpolarization of the luminal membrane, thus maintaining an electrical driving force for $\mathrm{HCO}_{3}{ }^{-}$secretion via either electrogenic SLC26 family anion exchangers [26] or CFTR itself [3]. However, in tissues that are thought to secrete little $\mathrm{HCO}_{3}^{-}$, such as the surface cells lining the larger airways and nasal tract $[17,11]$, where ASL $\left[\mathrm{Cl}^{-}\right]$is likely to remain high, then the mechanism we describe is less likely to be of major significance. Finally, the $\left[\mathrm{Cl}^{-}\right]_{\mathrm{o}}$ sensing site in CFTR that includes R899 on its extracellular face is a potential drug target for the correction of CF-causing gating mutants if a compound could be developed that mimicked the stimulatory effect of $\left[\mathrm{Cl}^{-}\right]_{\mathrm{o}}$ on the channel.

Acknowledgments This work was funded by grants from the Wellcome Trust (0789673/Z/06/Z) and Cystic Fibrosis Canada. We are grateful to Dr. T.C. Hwang for providing some of the CFTR mutants used in this study.

\section{Conflicts of interest None}

Open Access This article is distributed under the terms of the Creative Commons Attribution License which permits any use, distribution, and reproduction in any medium, provided the original author(s) and the source are credited.

\section{References}

1. Al-Nakkash L, Hu S, Li M, Hwang TC (2001) A common mechanism for cystic fibrosis transmembrane conductance regulator protein activation by genistein and benzimidazolone analogs. J Pharmacol Exp Ther 296(2):464-472

2. Aleksandrov L, Aleksandrov AA, Chang XB, Riordan JR (2002) The first nucleotide binding domain of cystic fibrosis transmembrane conductance regulator is a site of stable nucleotide interaction, whereas the second is a site of rapid turnover. $\mathrm{J}$ Biol Chem 277(18):15419-15425

3. Argent BE, Gray MA, Steward MC, Case RM (2012) In: L Johnson (ed) Physiology of the Gastrointestinal Tract. 5th edn. Elsevier, San Diego, pp 1399-1423

4. Baker JM, Hudson RP, Kanelis V, Choy WY, Thibodeau PH, Thomas PJ, Forman-Kay JD (2007) CFTR regulatory region interacts with NBD1 predominantly via multiple transient helices. Nat Struct Mol Biol 14(8):738-745

5. Basso C, Vergani P, Nairn AC, Gadsby DC (2003) Prolonged nonhydrolytic interaction of nucleotide with CFTR's NH2-terminal nucleotide binding domain and its role in channel gating. J Gen Physiol 122(3):333-348

6. Berger AL, Ikuma M, Welsh MJ (2005) Normal gating of CFTR requires ATP binding to both nucleotide-binding domains and hydrolysis at the second nucleotide-binding domain. Proc Natl Acad Sci U S A 102(2):455-460

7. Bompadre SG, Ai T, Cho JH, Wang X, Sohma Y, Li M, Hwang TC (2005) CFTR gating I: characterization of the ATP-dependent gating of a phosphorylation-independent CFTR channel (DeltaR-CFTR). J Gen Physiol 125(4):361-375

8. Bompadre SG, Cho JH, Wang X, Zou X, Sohma Y, Li M, Hwang TC (2005) CFTR gating II: effects of nucleotide binding on the stability of open states. J Gen Physiol 125(4):377-394

9. Bozoky Z, Krzeminski M, Muhandiram R, Birtley JR, Al-Zahrani A, Thomas PJ, Frizzell RA, Ford RC, Forman-Kay JD (2013) Regulatory R region of the CFTR chloride channel is a dynamic integrator of phospho-dependent intra- and intermolecular interactions. Proc Natl Acad Sci U S A 110(47):E4427-E4436

10. Broadbent SD, Wang W, Linsdell P (2014) Interaction between two extracellular loops influences the activity of the cystic fibrosis transmembrane conductance regulator chloride channel. Biochem Cell Biol. doi:10.1139/bcb-2014-00660829-8211

11. Cho DY, Hwang PH, Illek B, Fischer H (2011) Acid and base secretion in freshly excised nasal tissue from cystic fibrosis patients with DeltaF508 mutation. Int Forum Allergy Rhinol 1(2):123-127

12. Csanady L, Chan KW, Seto-Young D, Kopsco DC, Nairn AC, Gadsby DC (2000) Severed channels probe regulation of gating of cystic fibrosis transmembrane conductance regulator by its cytoplasmic domains. J Gen Physiol 116(3):477-500

13. Cui G, Rahman KS, Infield DT, Kuang C, Prince CZ, McCarty NA (2014) Three charged amino acids in extracellular loop 1 are involved in maintaining the outer pore architecture of CFTR. J Gen Physiol 144(2):159-179

14. Dalton J, Kalid O, Schushan M, Ben-Tal N, Villa-Freixa J (2012) New model of cystic fibrosis transmembrane conductance regulator proposes active channel-like conformation. J Chem Inf Model 52(7): $1842-1853$

15. Eckford PD, Li C, Ramjeesingh M, Bear CE (2012) Cystic fibrosis transmembrane conductance regulator (CFTR) potentiator VX-770 (ivacaftor) opens the defective channel gate of mutant CFTR in a phosphorylation-dependent but ATP-independent manner. J Biol Chem 287(44):36639-36649

16. Gadsby DC, Vergani P, Csanady L (2006) The ABC protein turned chloride channel whose failure causes cystic fibrosis. Nature 440(7083):477-483

17. Garland AL, Walton WG, Coakley RD, Tan CD, Gilmore RC, Hobbs CA, Tripathy A, Clunes LA, Bencharit S, Stutts MJ, Betts L, Redinbo MR, Tarran R (2013) Molecular basis for pH-dependent mucosal dehydration in cystic fibrosis airways. Proc Natl Acad Sci U S A 110(40):15973-15978

18. Gong X, Burbridge SM, Cowley EA, Linsdell P (2002) Molecular determinants of $\operatorname{Au}(\mathrm{CN})(2)(-)$ binding and permeability within the cystic fibrosis transmembrane conductance regulator $\mathrm{Cl}(-)$ channel pore. J Physiol 540(Pt 1):39-47 
19. Gong X, Linsdell P (2003) Molecular determinants and role of an anion binding site in the external mouth of the CFTR chloride channel pore. J Physiol 549(Pt 2):387-397

20. Hammerle MM, Aleksandrov AA, Riordan JR (2001) Diseaseassociated mutations in the extracytoplasmic loops of cystic fibrosis transmembrane conductance regulator do not impede biosynthetic processing but impair chloride channel stability. J Biol Chem 276(18):14848-14854

21. He L, Aleksandrov AA, Serohijos AW, Hegedus T, Aleksandrov LA, Cui L, Dokholyan NV, Riordan JR (2008) Multiple membranecytoplasmic domain contacts in the cystic fibrosis transmembrane conductance regulator (CFTR) mediate regulation of channel gating. J Biol Chem 283(39):26383-26390

22. Heda GD, Marino CR (2000) Surface expression of the cystic fibrosis transmembrane conductance regulator mutant DeltaF508 is markedly upregulated by combination treatment with sodium butyrate and low temperature. Biochem Biophys Res Commun 271(3):659-664

23. Jih KY, Hwang TC (2012) Nonequilibrium gating of CFTR on an equilibrium theme. Physiology Bethesda 27(6):351-361

24. Kogan I, Ramjeesingh M, Huan LJ, Wang Y, Bear CE (2001) Perturbation of the pore of the cystic fibrosis transmembrane conductance regulator (CFTR) inhibits its ATPase activity. J Biol Chem 276(15):11575-11581

25. Kopelman H, Corey M, Gaskin K, Durie P, Weizman Z, Forstner G (1988) Impaired chloride secretion, as well as bicarbonate secretion, underlies the fluid secretory defect in the cystic fibrosis pancreas. Gastroenterology 95(2):349-355

26. Lee MG, Ohana E, Park HW, Yang D, Muallem S (2012) Molecular mechanism of pancreatic and salivary gland fluid and $\mathrm{HCO} 3$ secretion. Physiol Rev 92(1):39-74

27. Li MS, Holstead RG, Wang W, Linsdell P (2011) Regulation of CFTR chloride channel macroscopic conductance by extracellular bicarbonate. Am J Physiol 300(1):C65-C74

28. Mornon JP, Lehn P, Callebaut I (2008) Atomic model of human cystic fibrosis transmembrane conductance regulator: membranespanning domains and coupling interfaces. Cell Mol Life Sci 65(16):2594-2612

29. O'Reilly CM, Winpenny JP, Argent BE, Gray MA (2000) Cystic fibrosis transmembrane conductance regulator currents in guinea pig pancreatic duct cells: inhibition by bicarbonate ions. Gastroenterology 118(6):1187-1196

30. Price MP, Ishihara H, Sheppard DN, Welsh MJ (1996) Function of Xenopus cystic fibrosis transmembrane conductance regulator (CFTR) Cl channels and use of human-Xenopus chimeras to investigate the pore properties of CFTR. J Biol Chem 271(41):25184-25191

31. Ramjeesingh M, Ugwu F, Stratford FL, Huan LJ, Li C, Bear CE (2008) The intact CFTR protein mediates ATPase rather than adenylate kinase activity. Biochem J 412(2):315-321

32. Riordan JR, Rommens JM, Kerem B, Alon N, Rozmahel R, Grzelczak Z, Zielenski J, Lok S, Plavsic N, Chou JL et al (1989) Identification of the cystic fibrosis gene: cloning and characterization of complementary DNA. Science (New York, NY) 245(4922):1066-1073

33. Robinson PJ, Smith AL, Sly PD (1990) Duodenal pH in cystic fibrosis and its relationship to fat malabsorption. Dig Dis Sci 35(10):1299-1304
34. Serohijos AW, Hegedus T, Aleksandrov AA, He L, Cui L, Dokholyan NV, Riordan JR (2008) Phenylalanine-508 mediates a cytoplasmic-membrane domain contact in the CFTR 3D structure crucial to assembly and channel function. Proc Natl Acad Sci U S A 105(9):3256-3261

35. Shcheynikov N, Kim KH, Kim KM, Dorwart MR, Ko SB, Goto H, Naruse S, Thomas PJ, Muallem S (2004) Dynamic control of cystic fibrosis transmembrane conductance regulator $\mathrm{Cl}(-) / \mathrm{HCO} 3(-)$ selectivity by external $\mathrm{Cl}(-)$. J Biol Chem 279(21):21857-21865

36. Sheppard DN, Welsh MJ (1999) Structure and function of the CFTR chloride channel. Physiol Rev 79(1 Suppl):S23-S45

37. Smith JJ, Welsh MJ (1992) cAMP stimulates bicarbonate secretion across normal, but not cystic fibrosis airway epithelia. J Clin Invest 89(4):1148-1153

38. Stratford FL, Ramjeesingh M, Cheung JC, Huan LJ, Bear CE (2007) The Walker B motif of the second nucleotide-binding domain (NBD2) of CFTR plays a key role in ATPase activity by the NBD1-NBD2 heterodimer. Biochem J 401(2):581-586

39. Thiagarajah JR, Song Y, Haggie PM, Verkman AS (2004) A small molecule CFTR inhibitor produces cystic fibrosis-like submucosal gland fluid secretions in normal airways. Faseb J 18(7):875-877

40. Vergani P, Lockless SW, Nairn AC, Gadsby DC (2005) CFTR channel opening by ATP-driven tight dimerization of its nucleotidebinding domains. Nature 433(7028):876-880

41. Verkman AS, Galietta LJ (2009) Chloride channels as drug targets. Nat Rev Drug Discov 8(2):153-171

42. Wang W, Linsdell P (2012) Alternating access to the transmembrane domain of the ATP-binding cassette protein cystic fibrosis transmembrane conductance regulator (ABCC7). J Biol Chem 287(13):1015610165

43. Wang XF, Zhou CX, Shi QX, Yuan YY, Yu MK, Ajonuma LC, Ho LS, Lo PS, Tsang LL, Liu Y, Lam SY, Chan LN, Zhao WC, Chung YW, Chan HC (2003) Involvement of CFTR in uterine bicarbonate secretion and the fertilizing capacity of sperm. Nat Cell Biol 5(10): 902-906

44. Wright AM, Gong X, Verdon B, Linsdell P, Mehta A, Riordan JR, Argent BE, Gray MA (2004) Novel regulation of cystic fibrosis transmembrane conductance regulator (CFTR) channel gating by external chloride. J Biol Chem 279(40):41658-41663

45. Zhou JJ, Fatehi M, Linsdell P (2008) Identification of positive charges situated at the outer mouth of the CFTR chloride channel pore. Pflugers Arch 457(2):351-360

46. Zhou JJ, Li MS, Qi J, Linsdell P (2010) Regulation of conductance by the number of fixed positive charges in the intracellular vestibule of the CFTR chloride channel pore. J Gen Physiol 135(3):229-245

47. Zhou JJ, Linsdell P (2009) Evidence that extracellular anions interact with a site outside the CFTR chloride channel pore to modify channel properties. Can J Physiol Pharmacol 87(5):387-395

48. Zhou Z, Wang X, Li M, Sohma Y, Zou X, Hwang TC (2005) High affinity ATP/ADP analogues as new tools for studying CFTR gating. J Physiol 569(Pt 2):447-457

49. Zhou Z, Wang X, Liu HY, Zou X, Li M, Hwang TC (2006) The two ATP binding sites of cystic fibrosis transmembrane conductance regulator (CFTR) play distinct roles in gating kinetics and energetics. J Gen Physiol 128(4):413-422 